\title{
Comparative genomic analysis of novel conserved peptide upstream open reading frames in Drosophila melanogaster and other dipteran species Celine A Hayden and Giovanni Bosco*
}

Address: Department of Molecular and Cellular Biology, University of Arizona, Tucson, AZ 85721, USA

Email: Celine A Hayden - chayden@email.arizona.edu; Giovanni Bosco* - gbosco@email.arizona.edu

* Corresponding author

Published: I February 2008

BMC Genomics 2008, 9:61 doi:10.1 |86/|47|-2164-9-61

This article is available from: http://www.biomedcentral.com//47I-2/64/9/6I

(c) 2008 Hayden and Bosco; licensee BioMed Central Ltd.

This is an Open Access article distributed under the terms of the Creative Commons Attribution License (http://creativecommons.org/licenses/by/2.0), which permits unrestricted use, distribution, and reproduction in any medium, provided the original work is properly cited.

\begin{abstract}
Background: Upstream open reading frames (uORFs) are elements found in the 5'-region of an mRNA transcript, capable of regulating protein production of the largest, or major ORF (mORF), and impacting organismal development and growth in fungi, plants, and animals. In Drosophila, approximately $40 \%$ of transcripts contain upstream start codons (uAUGs) but there is little evidence that these are translated and affect their associated mORF.

Results: Analyzing 19,389 Drosophila melanogaster transcript annotations and 666, I53 dipteran EST sequences we have identified 44 putative conserved peptide uORFs (CPuORFs) in Drosophila melanogaster that show evidence of negative selection, and therefore are likely to be translated. Transcripts with CPuORFs constitute approximately $0.3 \%$ of the total number of transcripts, a similar frequency to the Arabidopsis genome, and have a mean length of 70 amino acids, much larger than the mean length of plant CPuORFs ( 40 amino acids). There is a statistically significant clustering of CPuORFs at cytological band $57\left(\mathrm{p}=10^{-5}\right)$, a phenomenon that has never been described for uORFs. Based on GO term and Interpro domain analyses, genes in the uORF dataset show a higher frequency of ORFs implicated in mitochondrial import than the genome-wide frequency $(p<0.01)$ as well as methyltransferases $(p<0.02)$.

Conclusion: Based on these data, it is clear that Drosophila contain putative CPuORFs at frequencies similar to those found in plants. They are distinguished, however, by the type of mORF they tend to associate with, Drosophila CPuORFs preferentially occurring in transcripts encoding mitochondrial proteins and methyltransferases. This provides a basis for the study of CPuORFs and their putative regulatory role in mitochondrial function and disease.
\end{abstract}

\section{Background}

It is becoming increasingly clear that controlling protein levels post-transcriptionally is an important mechanism for growth and development in eukaryotic cells. Upstream start codons (uAUGs), AUGs found $5^{\prime}$ of the longest, or major, open reading frame (mORF), occur in $20-50 \%$ of eukaryotic mRNAs of a given genome [1-5]. When translation is initiated at a uAUG, these upstream ORFs (uORFs) can affect the protein level of the mORF with serious biological consequences. uORFs can regulate mORF protein production in response to starvation conditions $[6]$, polyamine concentrations $[7,8]$, and sucrose 
levels in the cell [9]. For example, the yeast General Control Nondepressible 4 (GCN4) transcript contains multiple uORFs that differentially regulate the protein level of a transcription factor-encoding mORF under starvation and non-starvation conditions. In turn, the protein produced from the mORF, the GCN4 protein, is essential to the transcriptional activation of some 40 genes involved in amino acid biosynthesis [6]. Because uORFs influence the levels of mORF protein, it is not surprising that disruption of the UAUG can lead to human disease such as thrombocythemia [10], a disease which is thought to arise as a result of increased mORF protein product, thrombopoietin (TPO). In addition, uAUGs occur in transcripts coding for oncogenes more frequently than other mammalian transcripts [11]. Indeed, oncogenes Mdm2 [12], her-2 [13], MYEOV [14], Bcl-2 [15], and SCL [16], all contain uORFs that affect the level of oncoproteins produced.

Potentially thousands of genes are regulated via uORFs, but there are no demonstrated examples of uORFs affecting mORF protein production in Drosophila or other insect species. Several uORF-containing genes have been well studied in fungi, plants, and mammals [17] and genomewide searches of conserved uORFs have been conducted using fungal, mammalian and plant transcripts [4,18-21]. Given the examples found in other eukaryotic species, it is plausible that uORFs fill a regulatory role in the arthropod lineage as well.

There is some evidence that regulatory uORFs may occur in insect species. Firstly, a Drosophila gene coding for a putative mannosyl transferase contains a uORF-mORF pair that seems to be evolutionarily conserved in insects [19]. Secondly, there are several examples of Drosophila dicistronic transcripts in which the first open reading frame could be regulatory to the second [22-24]. However, polycistronic transcripts do not all code for putative uORFs; many transcripts defined as polycistronic are initially transcribed as pre-mRNA with two or more ORFs, but are subsequently processed into separate monocistronic transcripts [25]. For this reason, we prefer to use the terminology 'uORF' to refer to an ORF (a) which is upstream of a mORF on a single mature mRNA, and (b) which is itself translated as a polypeptide distinct from protein translated from a mORF. In addition, polycistronic transcripts that are not processed into separate mRNA molecules are at times part of this uORF/mORF classification. The computational identification of dicistronic transcripts by Misra et al [22] resulted in the reannotation of 31 gene models, some of which may contain conserved uORF-mORF pairs. However, their search was limited to polycistronic transcripts with ORFs greater than 50 a.a., and it is known that uORF peptides as short as 6 a.a. can regulate mORF translation in mammals [26].
Their analysis also discarded overlapping ORFs, some of which are important for the regulation of mORFs [27].

To identify transcripts with uORFs that are likely to be translated, we took a comparative genomics approach using D. melanogaster transcript annotations, Anopheles gambiae transcript annotations, and dipteran expressed sequence tags (ESTs). Using this approach, we determined the prevalence, diversity, and genomic clustering of CPuORFs under negative selection in dipteran genomes and compared these findings to those reported for the plant lineage.

\section{Results and Discussion Identification of conserved peptide uORFs in D. melanogaster}

To determine the prevalence of uORFs most likely to be translated, Drosophila melanogaster release 4.3 transcript sequences $(19,389)$ were used to identify the largest, or major, ORF (mORF). Of these, 13,746 contain unique Flybase gene numbers, 5,851 of which contain one or more AUGs upstream of the mORF. This suggests that $43 \%$ of Drosophila mORF proteins could be affected in their expression level by translated uORFs. Our calculated percentage is slightly lower than previously reported Drosophila uAUG frequencies [2], but this discrepancy can be explained by the smaller dataset used in the previous study.

Putative dipteran homologs were found by comparing $D$. melanogaster mORFs to 666,153 NCBI ESTs using tBLASTn. Many of the EST sequences contained truncated uORF and mORF sequences, therefore the search was limited to species that diverged from D. melanogaster more than 15 Mya (non-melanogaster group species; AAA: 12 Drosophila Genomes Website) $[28,29]$, to increase detection of negative selection acting on short protein sequences. For each pair of homologs, global alignment of uORFs identified candidate CPuORFs and $K_{a} / K_{s}$ ratios were used to further verify evolutionary conservation of the uORF amino acid sequence. In addition, Flybase transcript annotations were used to discard any genes in which the putative CPuORF was fused to the MORF in any given transcript splice variant.

$K_{a} / K_{s}$ ratios $<1$ indicate that a sequence is under negative selection, $K_{a} / K_{s}$ ratios close to 1 imply that the sequence is undergoing drift, and $K_{a} / K_{s}$ ratios $>1$ suggest that the sequence is under positive selection. We found a total of $44 \mathrm{CPuORFs}$ with a $K_{a} / K_{s}$ ratio significantly less than one (Table 1 ; Additional File 1 ). Importantly, our $K_{a} / K_{s}$ ratio analysis distinguishes between high-scoring amino acid alignments that reflect conservation of nucleotide sequences versus alignments that reflect true evolutionary 
Table I: $K_{a} / K_{s}$ values of uORF and associated mORFs correlated to most distantly related organism containing uORF-mORF association in an EST

\begin{tabular}{|c|c|c|c|}
\hline CG identifier & uORF & mORF & $\begin{array}{l}\text { Most distantly related organism ( } \mathrm{NCBI} \text { accession \#), most closely shared taxonomic clas- } \\
\text { sification with } \mathrm{D} \text {. melanogaster }{ }^{\mathrm{a}}\end{array}$ \\
\hline CGI8624 & $0.11 * * * *$ & $0.06 * * * *$ & Boomic (CV448373), Arthropoda \\
\hline CGI2664 & $0.26 * *$ & $0.15 * * * *$ & Drovir (EB5685I7), Drosophila \\
\hline CGI2788/CG I7767 & $0.32 * * * *$ & $0.28 * * * *$ & Anogam (CD747020), Diptera \\
\hline CG337I3/CG337/4 & 0.06 ****** & $0.13^{* * *}$ & Carmae (DW250045), Pancrustacea \\
\hline CG3240 & $0.11 * * * * *$ & $0.11 * * * *$ & Dromoj (EB6|349|), Drosophila \\
\hline CG9960/CG9958 & $0.02 * * * *$ & $0.07 * * * *$ & Dapmag (DY0373460), Pancrustacea \\
\hline CG31917 & $0.00 * * * * *$ & $0.09 * * * *$ & Bommor (DY230769), Endopterygota \\
\hline CG31919/CG33995 & $0.10 * *$ & $0.31^{*}$ & Glomor (DV6I6490), Schizophora \\
\hline CGI8042 & $0.01 * * * * *$ & $0.29 *$ & Bommor (AU00398I), Endopterygota \\
\hline CG7400 & $0.10^{*}$ & $0.06 * * * *$ & Dropse (DR I24033), Sophophora \\
\hline CGI6974 & $0.00^{* *}$ & $0.14 * * * *$ & Dropse (DR I33486), Sophophora \\
\hline CG4824 & $0.04 * * *$ & $0.17 * * *$ & Dropse (DRI3|8|9), Sophophora \\
\hline CGI7325 & $0.08 * * * * *$ & $0.07 * * * *$ & Drogri (EB6 I I 588), Drosophila \\
\hline CGI0570 & $0.28 * *$ & $0.19 * * * *$ & Drogri (EB60I583), Drosophila \\
\hline CGII508 & $0.13^{* * * * *}$ & $0.54 * *$ & Glomor (DV620389), Schizophora \\
\hline CG8026 & $0.3 I^{*}$ & $0.04 * * * *$ & Drogri (EB598775), Drosophila \\
\hline CGI7759 (uORF2) & $0.33^{*}$ & $0.02 * * * *$ & Dromoj (EB608824), Drosophila \\
\hline CG3367I/CG33672 & $0.07 * * * *$ & $0.14 * * * *$ & Apimel (DB747777), Endopterygota \\
\hline CG6191 & $0.13^{* *}$ & $0.05^{* * * *}$ & Drogri (EB625487), Drosophila \\
\hline CG30100 & $0.08 * * * *$ & $0.09 * * * *$ & Ixosca (DN974785), Arthropoda \\
\hline CGI7725 & $0.00^{*}$ & $0.06 * * * *$ & Drowil (EB488086), Sophophora \\
\hline CG5469 & $0.10 * * * *$ & $0.07^{* * * * *}$ & Aedaeg (EB099927), Diptera \\
\hline CG33786/CG33785 & $0.03^{* *}$ & $0.16 * * * *$ & Bommor (BB992822), Endopterygota \\
\hline CG9865 (uORFI) & $0.12^{* * * * *}$ & $0.30 * * * *$ & Drowil (EB454746), Sophophora \\
\hline CG9865 (uORF2) & $0.07 * * * * *$ & $0.30 * * * *$ & Aedaeg (DV278474), Diptera \\
\hline CG9865 (uORF3) & $0.04^{* * * * *}$ & $0.30 * * * *$ & Acypis (CV847404), Neoptera \\
\hline CG9878 & $0.30 * *$ & $0.04 * * * *$ & Ixosca (AF483733), Arthropoda \\
\hline CG30290 & $0.00 * * * * *$ & $0.05^{*}$ & Carmae (DY308||6), Pancrustacea \\
\hline CGI2016 & $0.12^{* * * * * *}$ & $0.12 * * * *$ & Acypis (CN7620I5), Neoptera \\
\hline CG32573 & $0.42 * * *$ & $0.19 * * * *$ & Drowil (EB50I53I), Sophophora \\
\hline CGII989 & $0.04^{* * * * *}$ & $0.01 * * * *$ & Myzper (EE26I505), Neoptera \\
\hline CG7869 & $0.09 * * * * *$ & $0.12 * * * *$ & Dromoj (EB60888I), Drosophila \\
\hline CG7628 & $0.10^{* *}$ & $0.03 * * * *$ & Glomor (DV6I 243I), Schizophora \\
\hline CG9666 & $0.29 * * * *$ & $0.04 * * * *$ & Artfra (BQ605225), Pancrustacea \\
\hline CG2I 28 & $0.24^{* * * * *}$ & $0.00 * * * *$ & Bommor (BY9|4486), Endopterygota \\
\hline CG9288 & $0.16 * * * *$ & $0.17 * * * *$ & Aedaeg (DV427990), Diptera \\
\hline CG9924 & $0.08^{*}$ & $0.12^{* * * * *}$ & Drovir (EB563704), Drosophila \\
\hline CG3124I & $0.23 * * * *$ & $0.00 *$ & Dromoj (EB603524), Drosophila \\
\hline CG31178 & $0.31 * * *$ & $0.33^{* *}$ & Drovir (EB564030), Drosophila \\
\hline CG707I/CG34I3I & $0.08 * * * * *$ & $0.20 * * * *$ & Lutlon (AM099995), Diptera \\
\hline CGI0238 & $0.29 * * * *$ & $0.12^{* * * * *}$ & Taegut (DV95940I), Coelomata \\
\hline CG5116 & $0.15^{* *}$ & $0.16 * * * *$ & Drowil (EB489685), Sophophora \\
\hline CGI4550 & $0.13^{*}$ & $0.21^{* * * * *}$ & Bommor (CK562 I43), Endopterygota \\
\hline CG7950 & $0.35^{* * * * *}$ & $0.04 * * * *$ & Myzper (EE263186), Neoptera \\
\hline
\end{tabular}

a $D$. melanogaster taxonomic classification as described by $\mathrm{NCBI}$

b Abbreviations: Boomic, Boophilus microplus; Drovir, Drosophila virilis; Anogam, Anopheles gambiae; Carmae, Carcinus maenas; Dromoj, Drosophila mojavensis; Dapmag, Daphnia magna; Bommor, Bombyx mori; Glomor, Glossina morsitans; Dropse, Drosophila pseudoobscura; Drovir, Drosophila virilis; Drogri, Drosophila grimshawi; Apimel, Apis mellifera; Ixosca, Ixodes scapularis; Drowil, Drosophila willistoni; Aedaeg, Aedes aegypti; Acypis, Acyrthosiphon pisum; Myzper, Myzus persicae; Artfra, Artemia franciscana; Lutlon, Lutzomyia longipalpis; Taepyg, Taeniopygia guttata

* p-value < 0.05; $\mathrm{H}_{0}: K_{a} / K_{s}=1, \mathrm{H}_{A}: K_{a} / K_{s}<\mathrm{I}$

$* *$ p-value $<0.01$

$* * *$-value $<0.001$

$* * * * *$-value $<0.0001$ 
conservation of the amino acid sequence, and therefore are good indicators of translation.

Another indicator of translation is start codon context. Based on nucleotide frequencies of sequences surrounding mORFs, it is predicted that the Drosophila optimal consensus sequence is CAaaAUGg $[2,30]$, but no functional experiments have been conducted in insects to validate the strength of this initation context. Therefore, although the predominant CPuORF start context (AAaaAUGa) seems to be weaker than the predominant mORF context, it remains to be determined whether ribosomes initiate efficiently at the uORF AUG. It is also quite likely that initiation of some CPuORFs is dependent upon cellular conditions, as has been shown in various genes [6,31], leading to regulation of mORF protein levels.

A number of uORF-mORF pairs were used as positive controls for the modified uORF-Finder program. In a previous study, CG9865 was shown to contain a putative uORFmORF pair that has been conserved among distantly related insect species [19]. This gene was identified by our analysis, therefore validating our approach. Drosophila Tat-like (DTL), a gene containing a uORF with amino acid similarity in D. melanogaster and D. pseudoobscura [24] was also found by the uORF-Finder program. A third gene identified by our analysis, CG10238, is a bicistronic transcript encoding the small and large subunit of Molybdopterin synthase 2 (MOCS2) [23]. It is well conserved across distantly related eukaryotic species (see Additional File 2). In addition, 5 of the 31 dicistronic genes described by Misra et al [22] were shown to contain CPuORFs (Table 2; denoted by Misra and colleagues as CG33071ORFACG33071ORFB， Tim9b-CG12788， CG33009ORFACG33009ORFB， CG33005ORFA-CG33005ORFB, and snapin-CG9960, but subsequently renamed CG33713CG33714，CG12788-CG17767， CG33671-CG33672, CG33786-CG33785, and CG9960-CG9958, respectively). Many of the dicistronic transcripts identified by Misra et al [22] are transcripts with ORF pairs that are not well conserved among the Drosophila species. For example, the mei217-mei218uAUG is not conserved in any of the 11 other sequenced Drosophila genomes (UCSC D. melanogaster genome browser) [32], therefore it is not surprising that a number of the dicistronic genes were not identified by the uORF-Finder program. Additionally, it is likely that neither the D. melanogaster annotations nor the dipteran ESTs are representative of the complete transcript population within each species due to the incomplete annotation of 5' transcription start sites [33], and incomplete coverage of the genomes by ESTs.

Initially, 41 genes and $43 \mathrm{uORFs}$ showed evidence of mild to strong purifying selection $\left(K_{a} / K_{s}\right.$ ratio significantly $\left.<1\right)$, and an additional gene with one uORF was detected dur- ing subsequent duplication analysis (see below). The proportion of genes in the Drosophila genome showing evidence of CPuORFs is approximately $0.3 \%$ (42 genes out of 14,040 genes), which is similar to the frequency predicted for the Arabidopsis genome (0.4-0.5\%) [19]. The present study likely underestimates the prevalence of CPuORFs due to incomplete EST resources and potentially misannotated $5^{\prime}$ regions in $D$. melanogaster.

Consistent with calculated $K_{a} / K_{s}$ values, the majority of CPuORFs with a low $K_{a} / K_{s}$ ratio are present in lineages beyond the Drosophilidae (Table 1) and therefore have been conserved more than $40 \mathrm{My}$ (Assembly/Alignment/ Annotation of 12 Drosophila species) [28,29]. Those uORFs that exhibit a low $K_{a} / K_{s}$ ratio but are only found within Drosophila species may represent uORFs that have recently emerged within the Drosophila lineage but are nonetheless under mild to strong selection pressures.

\section{Insect CPuORFs are longer in average length than plant CPuORFs}

Two studies have shown that the length of a uORF can influence the ability of a ribosome to reinitiate scanning and translation initiation at a mORF [34,35]. The plant and mammalian cell systems used in these studies show that reinitiation at a downstream AUG is generally more efficient in the presence of shorter uORFs, and in plant protoplasts reinitiation drops sharply in constructs conwere carried out using viral components, and as such it is not clear whether these observations extend to mRNAs in a native eukaryotic cellular environment. Nonetheless, uORF length could play an important role in the regulation of mORFs, therefore we analyzed Drosophila CPuORFs in terms of their amino acid lengths. Initial characterization of the 44 putative CPuORFs under negative selection reveals a wide distribution of lengths, ranging from 15 to 179 amino acids (Table 2, Figure 1A).

To date, most, if not all, functionally characterized uORFs are smaller than 100 amino acids, but more than one fourth $(12 / 44)$ of $D$. melanogaster CPuORFs are above this size. In general, Drosophila CPuORFs seem to be larger than those found in plants. While $83 \%$ of Arabidopsis CPuORFs are between 21 and 60 amino acids in length (mean of 40 amino acids \pm 16 standard deviation; Figure 1B), the Drosophila uORF length distribution peaks between 41 and 80 amino acids (mean of 76 amino acids \pm 44 ; Figure 1A). These plant and insect datasets were not generated by comparing species with the same evolutionary distance but a more convincing comparison can be made by analyzing uORFs that have been conserved over more than 200 My: between Arabidopsis and rice, and between Drosophila and non-Brachycera lineages (e.g. Anopheles). The Arabidopsis distribution peak remains 
Table 2: Cytological distribution and peptide length of putative CPuORFs in Drosophila melanogaster

\begin{tabular}{|c|c|c|c|}
\hline $\begin{array}{l}\text { Flybase transcript identifier and uORF number } \\
\text { (FBtrXXXXX_\#) }\end{array}$ & CG identifier & Cytological gene location & uORF length (a.a.) \\
\hline FBtr007II40_I & CGI8624 & $7 C 2-7 C 2$ & 54 \\
\hline FBtr007I349_3 & CGI2664 & $8 \mathrm{ClI}-8 \mathrm{Cl} 3$ & 41 \\
\hline FBtr0074767_3 & CGI2788/CGI7767b & 18D3-|8D7 & 117 \\
\hline FBtr0077227_I & CG337/3/CG337/4b & 19F4-I9F4 & 90 \\
\hline FBtr0077747_I & CG3240 & $23 \mathrm{AI}-23 \mathrm{AI}$ & 179 \\
\hline FBtr0077737_2 & CG9960/CG9958b & $23 A 3-23 A 3$ & 134 \\
\hline FBtr0079037_2 & CG31917 & $25 \mathrm{Cl}-25 \mathrm{Cl}$ & 73 \\
\hline FBtr0079006_I & CG31919/CG33995 & $25 \mathrm{Cl}-25 \mathrm{Cl}$ & 44 \\
\hline FBtr0079695_3 & CGI8042 & 29D4-29D5 & 85 \\
\hline FBtr0080I33_I & CG7400 & 3IF4-3IF5 & 20 \\
\hline FBtr0080489_I & CGI6974 & 34A8-34A8 & 21 \\
\hline FBtr0080803_5 & CG4824 & 35E2-35E2 & 44 \\
\hline FBtr008II02_I & CGI7325 & 37A4-37A5 & 48 \\
\hline FBtr008II22_2 & CGI0570 & $37 A 4$ & 50 \\
\hline FBtr00888I7_5 & CGII508 & 44B3-44B3 & 150 \\
\hline FBtr0088610_3 & CG8026 & $45 \mathrm{~B} 3-45 \mathrm{~B} 3$ & 48 \\
\hline FBtr0087829_3 & CGI7759 & 49B8-49B9 & 31 \\
\hline FBtr0091650_2 & CG3367I/CG33672b & $49 \mathrm{~B} 10-49 \mathrm{~B} 10$ & 86 \\
\hline FBtr0087678_3 & CG6191 & 50B3-50B4 & 21 \\
\hline FBtr0087|40_I & CG30100 & $53 \mathrm{BI}-53 \mathrm{BI}$ & 70 \\
\hline FBtr008670I_I & CGI7725 & 55D3-55D3 & 27 \\
\hline FBtr0086654_7 & CG5469 & 55E5-55E5 & 121 \\
\hline FBtr0091786_I & CG33786/CG33785 & 57A8-57A9 & 108 \\
\hline FBtr007I680_7 & CG9865a (uORFI) & 57F7-57F7 & 65 \\
\hline FBtr007I680_5 & CG9865a (uORF2) & 57F7-57F7 & 84 \\
\hline FBtr007I680_4 & CG9865a (uORF3) & $57 F 7-57 F 7$ & 76 \\
\hline FBtr007I676_I & CG9878 & 57F8-57F8 & 65 \\
\hline FBtr007I672_I & CG30290 & 57F8-57F9 & 94 \\
\hline FBtr0073063_4 & CGI20I6 & 63DI-63DI & 81 \\
\hline FBtr00743I5_3 & CG32573 & 14F5-14F5 & 109 \\
\hline FBtr0076348_2 & CGII989 & 67D2-67D2 & 50 \\
\hline FBtr0076203_3 & CG7869 & $68 \mathrm{~A} 4-68 \mathrm{~A} 4$ & 68 \\
\hline FBtr00762I3_I & CG7628 & 68A7-68A8 & 18 \\
\hline FBtr007499I_5 & CG9666 & 76A3-76A3 & 129 \\
\hline FBtr0078767_I & $C G 2128$ & $83 A 4-83 A 4$ & 38 \\
\hline FBtr0082829_3 & CG9288 & $87 F|3-87 F| 3$ & 80 \\
\hline FBtr008287I_2 & CG9924 & 88A3-88A4 & 25 \\
\hline FBtr0083570_4 & CG3 $|24|$ & $90 \mathrm{FII}-90 \mathrm{FII}$ & 178 \\
\hline FBtr0084I38_3 & CG3II78 & $93 \mathrm{FI} 4-93 \mathrm{FI} 4$ & 40 \\
\hline FBtr00842II_I & CG707I/CG34I3/b & $94 A 6-94 A 6$ & 157 \\
\hline FBtr0084782_2 & CGI0238 & $96 \mathrm{Cl}-96 \mathrm{Cl}$ & 90 \\
\hline FBtr0084877_I & CG5II6 & $96 \mathrm{E} 2-96 \mathrm{E} 2$ & 15 \\
\hline FBtr0084974_2 & CGI4550 & $96 \mathrm{FIO}-96 \mathrm{FIO}$ & 111 \\
\hline FBtr0085563_I & CG7950 & 99D3-99D3 & 111 \\
\hline
\end{tabular}

a Gene with multiple CPuORFs in the same 5'UTR

b Different gene identifiers annotated as producing the same transcript; the first CG identifier predicts the translation of the $\mathrm{mORF}$ and the second CG identifier predicts the translation of the UORF.

essentially unchanged under these restrictions (mean of 39 amino acids \pm 13 ), whereas the distribution of Drosophila uORFs peaks at an even greater length, 81-100 amino acids (mean of 92 amino acids \pm 29 ; Figure 1C). Longer uORF lengths in Drosophila may reflect a need for stronger suppression of mORF translation than in plants, consistent with the observations of the above-mentioned cell culture studies. Alternatively, insect cells may exhibit more efficient reinitiation resulting in a requirement for longer uORFs to attenuate mORF translation.

\section{Physical mapping reveals clustering of CPuORFs independently of gene duplication}

In insect and mammalian genomes, clusters of closely related genes can sometimes occur, such as the Hox gene clusters [36]. To determine whether genes with uORFs 

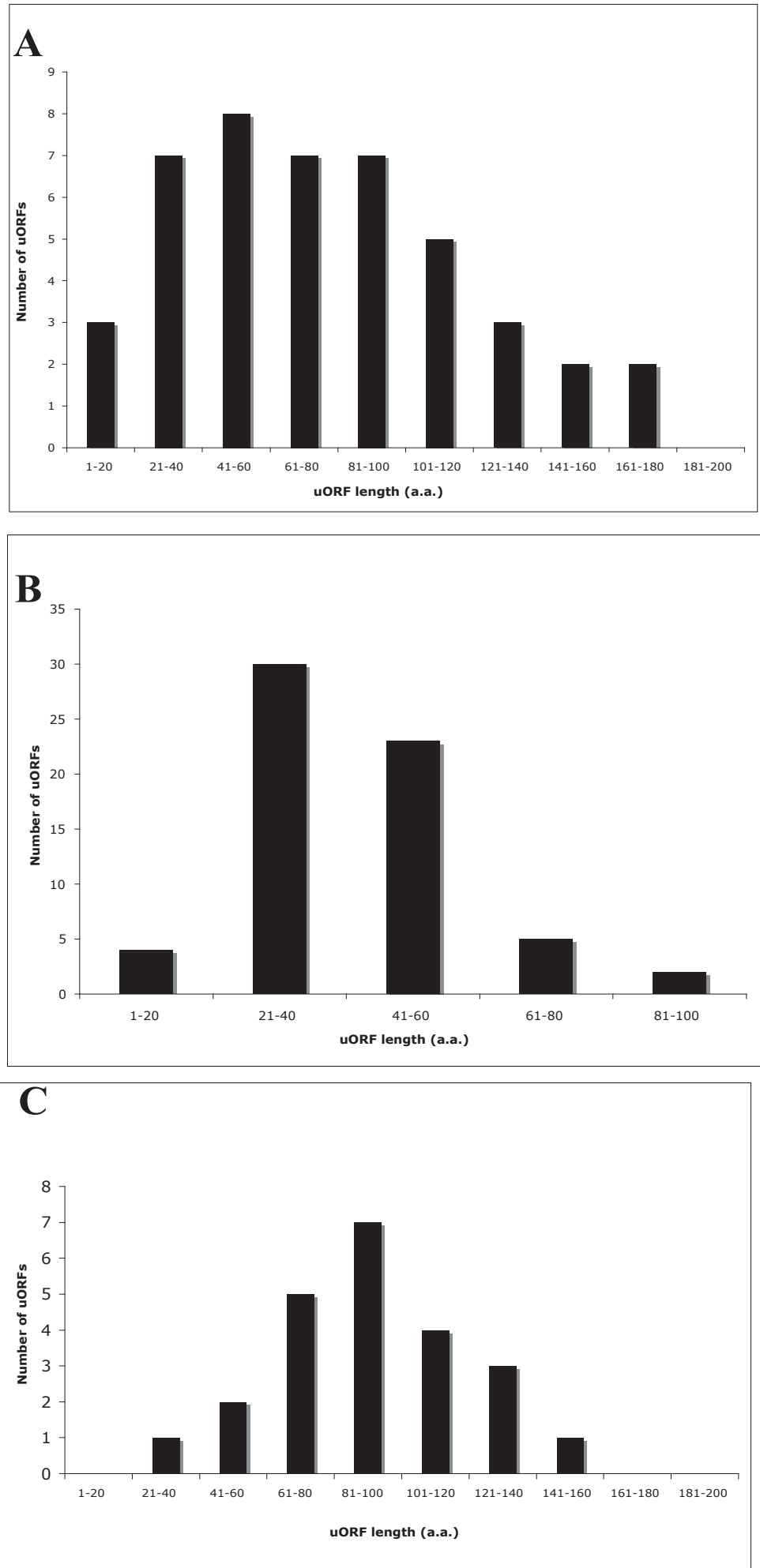

Figure I

Conserved peptide uORF length distribution. A. A total of 44 CPuORFs identified in Drosophila melanogaster, B.

CPuORFs in Arabidopsis thaliana as described by Hayden and Jorgensen [19], C. CPuORFs conserved between D. melanogaster and non-Brachycera species. 
cluster in certain parts of the genome, the $44 \mathrm{uORF}$ were placed on the D. melanogaster cytological map (Table 1) and compared to a random distribution (Methods). uORF frequencies were not statistically different from a randomly generated dataset except for a cluster of 6 uORFs residing on band $57\left(\mathrm{p}\right.$-value $\left.=10^{-5}\right)$, five of which fall on a much smaller segment of the chromosome, band 57F. Upon closer examination, some of these uORFs may have arisen as a result of tandem duplications; one uORF found in the CG30290 transcript as well as two uORFs found in the CG9865 transcript (uORF1 and uORF3) all contain twin $\mathrm{CX}_{9} \mathrm{C}$ motifs. Interestingly, the observed clustering is not dependent upon the putative duplication events of $\mathrm{CX}_{9} \mathrm{C}$ motif-containing uORFs. Eliminating the duplication bias by collapsing $\mathrm{CX}_{9} \mathrm{C}$-containing $\mathrm{uORF}$ to one representative, clustering is still statistically significant, with 4 uORFs on cytological band 57 (p-value $=0.004$ ) and $3 \mathrm{uORF}$ on band 57F (p-value $=0.0002)$. Therefore, the data suggest that there is a preponderance of both clustering and duplicate retention of uORFs on band 57 . Clustering at this region could be an indicator of chromatin interactions at this site that could mediate CPuORF regulation.

The twin $\mathrm{CX}_{9} \mathrm{C}$ motif is an integral part of coiled-coil helix, coiled-coil helix $(\mathrm{CHCH})$ domains, a domain previously implicated in uORF-mORF associations in group 8 plant uORFs [19]. In fact, the group 8-like Drosophila uORF member described in the plant study is uORF3 of CG9865. It is interesting to note that the plant group 8 uORF has consistently lost its duplicate copy during both recent and ancient polyploidy events whereas the Drosophila group 8 putative homologue may be retaining its duplicates. Different duplication retention histories could indicate that twin $\mathrm{CX}_{9} \mathrm{C}$ motif-containing ORFs play different roles in plants and animals.

\section{CPuORF-mORF pair duplicate retention is low within Drosophila melanogaster}

To determine whether there has been retention of uORFmORF pair duplicates within the Drosophila genome itself, the 41 mORFs with strongly conserved uORFs were compared to the D. melanogaster transcriptome. A single gene, CG17325 showed evidence of a duplicate copy, CG10570, in which the UORF-mORF pair is conserved (See Additional File 3). CG10570 was not detected by our program due to the short length of its mORF $(<100$ amino acids), therefore this gene was added to our list of CPuORFs following our duplication analysis (Tables 1 and 2). CG17325 and CG10570 reside adjacent to one another on chromosome 2, band 37A4-A5, and are transcribed on opposite strands away from one another. The close proximity of the genes suggests a segmental duplication gave rise to the two genes, both of which are conserved throughout the Drosophila lineage and exhibit a $K_{a} /$
$K_{s}$ ratio $<0.28$ (Table 1 ). This duplication presumably occurred more than 40 Mya since both loci are present in D. melanogaster, D. grimshawi, and D. virilis. Unlike the extensive uORF-mORF duplication retention history of the Arabidopsis genome, CG17325 and CG10570 were the only example of gene duplicate retention in Drosophila.

\section{GO term and protein domain analysis suggest a link between CPuORFs and both mitochondrial proteins and methyltransferases}

Further differences between plant and insect CPuORFs were observed following gene ontology (GO) term analysis. GO term frequencies in the D. melanogaster genome were compared to frequencies in the insect uORF dataset to look for overrepresentation of terms. P-values were determined using the Bonferroni correction method, a method that accounts for multiple comparisons and calculates a conservative p-value. Also, the recent tandem duplicate (see above) was not included in the analysis to eliminate bias from recent duplication events. Because GO terms have been assigned to all ORFs found in bicistronic transcripts, GO terms were extracted for both uORF and mORF gene identifiers, designated hereafter as the uORF dataset (41 mORFs and 7 uORFs). This analysis differs from previous analyses in plants; it not only identifies 1) classes of mORF proteins that tend to associate with CPuORFs, but it also identifies 2) ORFs that preferentially associate with other ORFs on a single transcript. In plants, a large proportion of CPuORFs associate with mORFs encoding transcription factors, however this trend was not observed in insects. Instead, mORF proteins showing evidence of N-methyltransferase activity (GO term for CG9666 and CG9960 mORFs; Table 3) tend to associate with CPuORFs $(\mathrm{p}=0.02)$. This methyltransferase activity may act on DNA or RNA, since both types of Interpro domains are overrepresented in these two genes.

Additionally, overrepresentation of GO term 'protein import into the mitochondrial inner membrane' is driven by two proteins in the Drosophila uORF dataset, CG9878 (Translocase of inner membrane 10, Tim10) and CG17767 (Tim9b), which contain the Interpro Zn-finger Tim10/ DDP-type domain $(\mathrm{p}=0.01)$. Unlike the overrepresented methyltransferase domain, the Tim10/DDP-type domain is not limited to the mORFs, but appears in either the uORF or mORF, demonstrating that these ORFs show a preference for associating with other ORFs in a transcript. Specifically, Tim 10 is encoded by the mORF of its transcript while Tim9b is encoded by the uORF. This does not imply that Tim9b does not act as a regulatory UORF, however. Tim9b may act both as a chaperone in the intermembrane space, as well as a regulatory element controlling the translation of its associated mORF. 
Table 3: Gene Ontology term and InterPro domain overrepresentation in uORF dataset as determined by Genemerge

\begin{tabular}{|c|c|c|c|c|}
\hline $\begin{array}{l}\text { GO term or Interpro } \\
\text { reference number }\end{array}$ & $\begin{array}{l}\text { GO term or Interpro } \\
\text { domain }\end{array}$ & Genome frequency & $\begin{array}{c}\text { Frequency in uORF } \\
\text { dataset }\end{array}$ & $\begin{array}{l}\text { Bonferroni corrected } \mathrm{P} \text { - } \\
\text { value }\end{array}$ \\
\hline GO:0008I70 (MF) & $\mathrm{N}$-methyltransferase activity & $10 / 14601$ & $2 / 481$ & 0.015 \\
\hline GO:0045039 (BP) & $\begin{array}{l}\text { protein import into } \\
\text { mitochondrial inner } \\
\text { membrane }\end{array}$ & $6 / 14601$ & $2 / 48^{2}$ & 0.008 \\
\hline IPR002296 & $\begin{array}{l}\text { N6 adenine-specific DNA } \\
\text { methyltransferase, NI } 2 \text { class }\end{array}$ & $4 / 14040$ & $2 / 481$ & 0.004 \\
\hline IPR00024I & Putative RNA methylase & $3 / 14040$ & $2 / 48$ I & 0.002 \\
\hline IPR0042I7 & Zinc finger, Tim I0/DDP-type & $5 / 14040$ & $2 / 48^{2}$ & 0.006 \\
\hline
\end{tabular}

MF, molecular function; BP, biological process

I GO term or Interpro domain observed in CG9666 and CG9960

2 GO term or Interpro domain observed in CG9878 (Tim I0) and CGI 7767 (Tim9b)

In support of a model in which mitochondrial proteins preferentially associate with other ORFs on a single transcript, a further connection to the mitochondrial inner membrane is found when examining other genes in the uORF dataset. The CG8026 mORF encodes a putative mitochondrial folate transport protein $[37,38]$ (Table 4). Interestingly, this trend may extend to the mammalian lineage, exemplified by the human Uncoupling protein 2 (UCP2) mORF, a putative inner mitochondrial membrane transporter. The UCP2 mORF is not only associated with what appears to be a CPuORF, but it is regulated by its UORF in a glutamine-dependent manner [39]. B-cell lymphoma $2(B C L-2)$ is another mammalian oncogene that produces a protein from its mORF, BCL-2, which is localized to mitochondria [40] and is associated with a functional uORF [15].

Other Drosophila genes also have potential links to the mitochondrion, such as CG18624, a putative NADH dehydrogenase that is predicted to act in mitochondrial electron transport (Table 4). Also, uORF1 of CG9865 is a putative homolog of p8Mature T-Cell Proliferation 1 (p8MTCP1), an ORF that is transcribed on the same mRNA as p13MTCP1, is targeted to mitochondria [41], and may play a role in oncogenesis $[42,43]$. CG9865 uORF1 has a twin $\mathrm{CX}_{9} \mathrm{C}$ motif, as do p8MTCP1 and other proteins targeted to mitochondria, namely yeast proteins Mitochondrial Ribosomal Protein 10 (Mrp10p) [44], Cytochrome Oxidase 19 (Cox19p) [45], Cytochrome Oxidase $17(\operatorname{Cox} 17 p)$ [46], and Mitochondrial intermembrane space Import and Assembly 40 (Mia40p) [47]. In humans, the twin $\mathrm{CX}_{9} \mathrm{C}$ motif found in Mia40p is required for import and stable accumulation of Mia40 in the intermembrane space [48]. Several genes in the uORF dataset contain ORFs with $\mathrm{CX}_{9} \mathrm{C}$ motifs, such as uORFs 1 and 3 of CG9865, the uORFs of CG30290 and CG9288, and the mORF of CG7950 (See Additional File 2). These open reading frames could be interacting with other ORFs on the same transcript to target them to the mitochondria or to form a stabilizing protein complex.
It is possible that these ORF associations are vestiges of ancient prokaryotic operons that originated in the mitochondrion and were transferred to the nuclear genome over time. This hypothesis runs counter to the prevailing thought that mitochondrial proteins involved in transport are generally of eukayotic origin [49]. Regardless of their origin, nuclear ORFs coding for mitochondrial proteins may maintain an association with other ORFs on a single transcript over long periods of evolutionary time for several reasons. Both ORFs may be co-regulated at the transcriptional level and be required at similar times in development, thus providing more efficient transcription of DNA. Alternatively, the uORF may be regulating expression of the mORF with important biological consequences. These possibilities are not mutually exclusive and further experimentation will be required to determine whether this energy-producing organelle is influenced by the translational regulation of UORF-mORF pairs on single transcripts.

Interestingly, the trend in animal mitochondrial ORFs was not observed in plants. Instead, plant uORFs tend to associate with mORFs encoding transcription factors [19]. Perhaps these unique characteristics reflect fundamental differences in the two eukaryotic lineages. Despite their differences, plants and animals both seem to contain uORF-mORF pairs involved in a wide range of biochemical and regulatory pathways (Table 4). There is some evidence in the literature that transcripts with uORFs can occur in similar biochemical pathways, such as genes affecting the polyamine biochemical pathway [50], but this is the exception rather than the rule and no additional examples have been born out by our analyses. To facilitate future studies of these elements, all CPuORF annotations will be submitted to Flybase.

\section{Conclusion}

The identification and characterization of putative CPuORFs has established a knowledge base from which many hypotheses have been generated and can now be 
Table 4: Predicted function and biological processes of uORF-mORF pairs in Drosophila

\begin{tabular}{|c|c|c|c|c|}
\hline CG identifier & Gene name synonyms ${ }^{a}$ & Inferred function ${ }^{a}$ & $\begin{array}{l}\text { Inferred biological proc- } \\
\text { ess }^{\text {a }}\end{array}$ & Supporting evidence \\
\hline CGI8624 & & $\begin{array}{l}\text { Putative NADH } \\
\text { dehydrogenase }\end{array}$ & $\begin{array}{l}\text { Mitochondrial electron } \\
\text { transport }\end{array}$ & $\begin{array}{l}\text { Pfam domain; GO term } \\
\text { designation }\end{array}$ \\
\hline CGI2664 & Id I 4, fendb & Unknown & Neuromuscular development & {$[61,62]$} \\
\hline CGI2788/CGI7767c & Tim $9 b^{b}$ (uORF) & $\begin{array}{l}\text { Mitochondrial inner } \\
\text { membrane translocase subunit } \\
\text { (uORF) }\end{array}$ & $\begin{array}{l}\text { Transport across } \\
\text { mitochondrial inner } \\
\text { membrane (uORF) }\end{array}$ & Interpro domain \\
\hline CG337/3/CG337/4c & & $\begin{array}{l}\text { Acyl-CoA binding (mORF) } \\
\text { RNA binding (uORF) }\end{array}$ & Unknown & Interpro domain \\
\hline CG3240 & $\operatorname{Rad} / \mathrm{b}$ & $\begin{array}{l}\text { Putative } 3^{\prime}->5^{\prime} \text { exonuclease } \\
\text { activity }\end{array}$ & DNA repair & {$[63,64]$} \\
\hline CG9960/CG9958c & snapin (uORF) & $\begin{array}{l}\text { Putative methyltransferase } \\
\text { (mORF) Putative Biogenesis of } \\
\text { Lysosome-related Organelles } \\
\text { Complex-I-like (BLOC-I-like) } \\
\text { subunit (uORF) }\end{array}$ & $\begin{array}{l}\text { Biogenesis of lysosome- } \\
\text { related organelles (eg. } \\
\text { melanosomes and platelet } \\
\text { dense granules; uORF) }\end{array}$ & $\begin{array}{l}\text { [65] (uORF) Interpro domain } \\
\text { (mORF) }\end{array}$ \\
\hline CG31917 & TFB5 (uORF) & Putative TFIIH subunit (uORF) & $\begin{array}{l}\text { Transcription and DNA } \\
\text { repair (uORF) }\end{array}$ & {$[66,67]$; Interpro domain } \\
\hline CG31919/CG33995c & & $\begin{array}{l}\text { Ankyrin repeat, protein- } \\
\text { protein interactions }\end{array}$ & $\begin{array}{l}\text { Target of transcription factor } \\
\text { Glial cells missing }(\mathrm{Gcm}) \\
\text { involved in neuronal } \\
\text { development and function }\end{array}$ & Interpro domain; [68] \\
\hline CGI8042 & $\operatorname{lmg} \mathrm{b}$ & $\begin{array}{l}\text { Putative component of } \\
\text { Anaphase Promoting } \\
\text { Complex (uORF) }\end{array}$ & $\begin{array}{l}\text { Mitosis; Neural development } \\
\text { (unclear whether it is the } \\
\text { uORF, mORF or both) }\end{array}$ & $\begin{array}{l}{[69,70] \text {; Flybase personal }} \\
\text { communication FBrf0 I 25046; } \\
\text { [7I]; NCBI Conserved } \\
\text { Domain Search }\end{array}$ \\
\hline CG7400 & Fatp ${ }^{b}$ & $\begin{array}{l}\text { Putative very-long-chain fatty } \\
\text { acyl-CoA synthetase }\end{array}$ & Fatty acid metabolism & {$[72]$} \\
\hline CGI6974 & Member of LIG superfamilyb & $\begin{array}{l}\text { Leucine-rich repeat and } \\
\text { Immunoglobulin domain- } \\
\text { containing protein }\end{array}$ & Unknown & {$[73,74]$} \\
\hline CG4824 & $\mathrm{Bic} \mathrm{Cb}^{\mathrm{b}}$ & RNA binding protein & $\begin{array}{l}\text { Anterior-Posterior } \\
\text { patterning }\end{array}$ & [75-77] \\
\hline CGI7325 & & Unknown & Unknown & \\
\hline CGI0570 & & Unknown & Unknown & \\
\hline CGII508 & DmSNAP50, DmPBP49b & $\begin{array}{l}\text { Subunit of an snRNA } \\
\text { transcriptional activator } \\
\text { protein }\end{array}$ & $\begin{array}{l}\text { Transcription of splicing } \\
\text { factors }\end{array}$ & [78] \\
\hline CG8026 & & Mitochondrial carrier protein & $\begin{array}{l}\text { Mitochondrial folate } \\
\text { transport }\end{array}$ & {$[37,38]$} \\
\hline CGI7759b (uORF2) & Galpha49B, Gq $\alpha^{\text {b }}$ & G-protein subunit & $\begin{array}{l}\text { Photoreceptor signal } \\
\text { transduction; Axonal } \\
\text { guidance }\end{array}$ & {$[79-81]$} \\
\hline CG3367I/CG33672c & & $\begin{array}{l}\text { Mevalonate kinase (mORF); } \\
\text { BolA-like protein, putative } \\
\text { nucleic acid binding protein } \\
\text { (uORF) }\end{array}$ & $\begin{array}{l}\text { Isoprenoid production } \\
\text { (mORF) }\end{array}$ & {$[82,83]$} \\
\hline CG6191 & & Unknown & Unknown & \\
\hline CG30100 & & Translation release factor & Translation termination & GO term designation \\
\hline CGI7725 & Pepck ${ }^{\mathrm{b}}$ & $\begin{array}{l}\text { Putative phosphoenolpyruvate } \\
\text { carboxykinase }\end{array}$ & $\begin{array}{l}\text { Gluconeogenesis; Starvation; } \\
\text { Glyceroneogenesis }\end{array}$ & {$[84-86]$} \\
\hline CG5469 & Gint $3^{b}$ & $\begin{array}{l}\text { Ubiquitin regulatory } X \text { domain } \\
(U B X) \text {, putative RNA binding }\end{array}$ & Unknown & [87]; FBrf0I89302 \\
\hline CG33786/CG33785c & & Unknown & $\begin{array}{l}\text { Translation (mORF) } \\
\text { Transcription (uORF) }\end{array}$ & Interpro domain \\
\hline CG9865b (uORFI) & & Putative mannosyl transferase & Unknown & Interpro domain \\
\hline CG9865b (uORF2) & & Putative mannosyl transferase & Unknown & Interpro domain \\
\hline CG9865b (uORF3) & & Putative mannosyl transferase & Unknown & Interpro domain \\
\hline CG9878 & $\operatorname{Tim} 10^{\mathrm{b}}$ & $\begin{array}{l}\text { Putative inner mitochondrial } \\
\text { membrane translocase }\end{array}$ & $\begin{array}{l}\text { Protein transport across } \\
\text { mitochondrial membrane }\end{array}$ & [88] \\
\hline CG30290 & & Putative flavoprotein enzyme & Unknown & Interpro domain \\
\hline CGI20I6 & & Unknown & Unknown & \\
\hline CG32573 & & Unknown & Unkown & \\
\hline
\end{tabular}


Table 4: Predicted function and biological processes of uORF-mORF pairs in Drosophila (Continued)

\begin{tabular}{|c|c|c|c|c|}
\hline CGII989 & $\operatorname{Ard} I^{b}$ & $\begin{array}{l}\text { Putative } \mathrm{N} \text {-Acetyltransferase } \\
\text { catalytic subunit }\end{array}$ & Unknown & [89]; Interpro domain \\
\hline CG7869 & $S u \cup R^{b}$ & DNA binding & Endoreplication & {$[90,91]$} \\
\hline CG7628 & & Phosphate transporter & Phosphate transport & Interpro domain \\
\hline CG9666 & & Putative methyltransferase & Unknown & Interpro domain \\
\hline CG2I 28 & $\mathrm{Hdac}^{\mathrm{b}}$ & Histone deacetylase & $\begin{array}{l}\text { Wing development; } \\
\text { Chromatin remodeling }\end{array}$ & {$[92,93]$} \\
\hline CG9288 & & Pyruvate kinase & Unknown & Interpro domain \\
\hline CG9924 & $R d x^{b}$ & Unknown & $\begin{array}{l}\text { Regulator of Hedgehog } \\
\text { response (growth and } \\
\text { development) }\end{array}$ & {$[94,95]$} \\
\hline CG3I24I & $D T L^{\mathrm{b}}$ & Putative RNA methylase & Late larval development & [24]; Interpro domain \\
\hline CG31178 & & Unknown & Unknown & \\
\hline CG707I/CG34I/3/c & & Unknown & Unknown & \\
\hline CGI0238 & MOCS $2^{b}$ & $\begin{array}{l}\text { Molybdopterin synthase large } \\
\text { subunit (mORF) and small } \\
\text { subunit (uORF) }\end{array}$ & $\begin{array}{l}\text { Production of molybdopterin; } \\
\text { Implicated in mammalian } \\
\text { neurological damage }\end{array}$ & {$[23,96]$} \\
\hline CG5II6 & & Putative GTP-binding protein & Unknown & Interpro domain \\
\hline CGI4550 & & $\begin{array}{l}\text { Putative phosphatidylinositol } \\
\mathrm{N} \text { - } \\
\text { acetylglucosaminyltransferase } \\
\text { subunit } \mathrm{P} \text { (mORF); Pccl-like } \\
\text { transcription factor (uORF) }\end{array}$ & Unknown & Interpro domains \\
\hline CG7950 & & $\begin{array}{l}\text { Putative tRNA processing } \\
\text { enzyme subunit (uORF) }\end{array}$ & tRNA processing (uORF) & Interpro domain \\
\hline
\end{tabular}

a refers to mORF unless otherwise noted

bfend, Forked end; Tim9b, Translocase of inner membrane 9b; RadI, Radiation insensitive I; Img, Lemming;Fatp, Fatty acid transport protein; LIG, Leucine-Rich Repeat and Immunoglobulin-containing protein (MacLaren et al, 2004); BicC, Bicaudal C; DmSNAP50/DmPBP49, snRNA activator protein 50/Proximal Sequence Element-Binding Protein 49;Galpha49B, G-protein alpha49B; Pepck, Phosphoenolpyruvate carboxykinase; Gint3, GDI interacting protein 3; Tim 10, Translocase of inner membrane; SuUR, Suppressor of underreplication; Ard I, Arrest defective I; Hdac3, Histone deacetylase 3; Rdx, Roadkill (Kent et al, 2006); DTL, Drosophila Tat-like; MOCS2, molybdopterin synthase 2

tested. CPuORFs in dipterans show similarities to their plant counterparts in terms of their prevalence within the genome and diversity of sequence, but differ in their greater average length, their genome clustering, and their preferential association with methyltransferases. In addition, the present analysis has shown a significant correlation between mitochondrially-targeted proteins and transcripts containing uORFs, an observation that could lead to important discoveries impacting our understanding of human disease. Given the wealth of genetic tools available in Drosophila, this model system is ideally suited to the basic understanding of uORF-containing transcripts and post-transcriptional regulation.

\section{Methods}

\section{Identification of conserved peptide uORFs}

Drosophila melanogaster transcript sequences, release 4.3 $(19,389$ sequences) were downloaded from Flybase [51], Anopheles gambiae transcript sequences, build $3.4(14,127$ sequences) were downloaded from Ensembl [52], and dipteran expressed sequence tags (ESTs) $(666,153)$ were downloaded from NCBI [53] December 15, 2006. Because the melanogaster group members (includes $D$. simulans, D. yakuba, D. erecta, and D. ananassae) diverged from $D$. melanogaster relatively recently $[28,29]$, their transcript sequences are of limited use in detecting strong negative selection over short sequence lengths due to the accumulation of few synonymous and non-synonymous substitutions. Therefore these species were excluded from this first comparison, as were D. melanogaster ESTs.

Comparative analysis of D. melanogaster and A. gambiae sequences was performed using uORF-Finder [19], a program that identifies the longest open reading frame of a transcript in the first species (defined as the mORF), finds the putative homolog in the second species, and aligns all open reading frames upstream of these homologs to identify putatively conserved uORFs. uORF-Finder was designed to compare full-length cDNA sequences from two species, therefore to accommodate a D. melanogaster full-length transcript-to-dipteran EST comparison, the program was modified and putative homologs in the ESTs were identified using the first 100 amino acids of the $D$. melanogaster mORFs. uORF size was also limited to 200 amino acids (no additional uORFs were found when uORF size was limited to 300 a.a.).

The presence of putative CPuORFs was established in at least three different species by either extracting the first 100 amino acids of the $D$. melanogaster mORF sequence and searching the NCBI EST database using tBLASTn for putative homologs with conserved uORF sequences, or by scanning the UCSC D. melanogaster genome browser and inspecting other Drosophila genomes for conservation of 
uORF start and stop codons [32]. Any putative uORF sequences that showed evidence of in-frame fusion with the mORF on the UCSC browser (in an alternative splice form, for example) were not included in the final list of CPuORF-containing transcripts.

\section{Calculation of $K_{\mathrm{a}} / K_{\mathrm{s}}$}

The $K_{a} / K_{s}$ ratio was determined using pairwise_kaks.PLS (version 1.7) [54] and is derived from the highest scoring BLAST homolog in the D. melanogaster-dipteran high scoring pairs. Both the approximate method (option -kaks yn00) and the maximum likelihood method (-kaks codeml) were used. Only the approximate method calculation is reported in Table 1 due to the typically short evolutionary distance between the organisms found in the highest scoring BLAST pairs. The Nei-Gojobori p-distance model was used to test for purifying selection (Null hypothesis $K_{a}=K_{s}$; alternate hypothesis $K_{a}<K_{s}$ ). MEGA4 default settings were used to run codon-based Z-test analyses [55] on highest scoring BLAST homologs.

\section{Cytological distribution of uORFs}

To determine whether the 44 uORFs were randomly distributed along the Drosophila chromosomes relative to annotated transcript positions, a perl script was written to generate a random distribution of 44 positions along the chromosomes. Cytological positions for each CG gene identifier were extracted from $D$. melanogaster release 4.3 gene annotations [51], from which 44 positions were randomly chosen. This ensured that clustering would not simply reflect gene rich regions. The number of 'hits' within a given cytological band were tallied, and the entire process was iterated 30,000 times, providing a random distribution of 'hits' at any given band when 44 positions were picked across the entire genome. The random distributions were then used to provide a p-value for the observed number of uORFs within a given cytological band.

\section{Gene Ontology, Pfam domain, and Interpro domain retrieval and analysis}

Over- and under-representation of Gene Ontology (GO) terms in the uORF dataset (41 mORFs and 7 uORFs with associated GO terms) versus the D. melanogaster genome was determined using Genemerge v.1.2 [56], a program which provides a Bonferroni-corrected p-value. Association files were derived from Gene Ontology website files (D. melanogaster annotation received from Flybase March 13, 2007) [57], and from the BioMart website [58] (Ensembl Gene ID, Pfam ID, and Interpro ID numbers obtained; downloaded files are based on D. melanogaster genome release 4.3). Description files were derived from GO term files [59] (gene_ontology.obo.zip), and from Interpro files [60].

\section{Abbreviations}

Upstream open reading frame (uORF), Major open reading frame (mORF), Upstream start codon (uAUG), Conserved peptide upstream open reading frame (CPuORF), General Control Nondepressible 4 (GCN4), Thrombopoietin (TPO), Expressed sequence tag (EST), Drosophila Tat-like (DTL),Molybdopterin synthase 2 (MOCS2), Gene ontology (GO), Translocase of inner membrane 10 (Tim10), Translocase of inner membrane 9b (Tim9b), Uncoupling protein 2 (UCP2), B-cell lymphoma 2 (BCL-2), p8 mature T-cell proliferation(p8MTCP1), Mitochondrial Ribosomal Protein 10 (Mrp10p), Cytochrome Oxidase 19 (Cox19p), Cytochrome Oxidase 17 (Cox17p), Mitochondrial intermembrane space import and assembly 40 (Mia40p)

\section{Authors' contributions}

$\mathrm{CAH}$ and GB conceived and designed the experiments. $\mathrm{CAH}$ carried out the analysis and drafted the manuscript. GB provided critical feedback for the final version. Both authors have read and approved the final manuscript version.

\section{Additional material}

\section{Additional file 1}

Conserved peptide $u O R F$ sequences. Conserved peptide $u O R F$ and associated mORF amino acid sequences in Drosophila melanogaster. Click here for file

[http://www.biomedcentral.com/content/supplementary/14712164-9-61-S1.txt]

\section{Additional file 2}

$u O R F$ and mORF sequences and alignments. Amino acid sequences and alignment of insect conserved peptide uORFs and associated mORFs. Click here for file

[http://www.biomedcentral.com/content/supplementary/14712164-9-61-S2.txt]

\section{Additional file 3}

CG17325/CG10570 sequences and alignment. Amino acid sequences and alignment of putatively duplicated D. melanogaster genes,

CG17325 and CG10570.

Click here for file

[http://www.biomedcentral.com/content/supplementary/14712164-9-61-S3.txt]

\section{Acknowledgements}

This research was funded by an NIH IRACDA fellowship to CAH (Grant \#GM000708), and an NIH ROI grant to GB (GM069462).

\section{References}

I. Cavener DR, Cavener BA: Translation start sites and mRNA leaders. In An Atlas of Drosophila genes Edited by: Maroni G. New York, Oxford University Press; 1993:359-377.

2. Rogozin IB, Kochetov AV, Kondrashov FA, Koonin EV, Milanesi L: Presence of ATG triplets in $5^{\prime}$ untranslated regions of 
eukaryotic cDNAs correlates with a 'weak' context of the start codon. Bioinformatics 200I, 17:890-900.

3. Churbanov A, Rogozin IB, Babenko VN, Ali H, Koonin EV: Evolutionary conservation suggests a regulatory function of AUG triplets in 5'-UTRs of eukaryotic genes. Nucleic Acids Res 2005, 33:5512-5520.

4. Galagan JE, Calvo SE, Cuomo C, Ma LJ, Wortman JR, Batzoglou S, Lee SI, Basturkmen M, Spevak CC, Clutterbuck J, Kapitonov V, Jurka J, Scazzocchio C, Farman M, Butler J, Purcell S, Harris S, Braus GH, Draht O, Busch S, D'Enfert C, Bouchier C, Goldman GH, Bell-Pedersen D, Griffiths-Jones S, Doonan JH, Yu J, Vienken K, Pain A, Freitag M, Selker EU, Archer DB, Penalva MA, Oakley BR, Momany M, Tanaka T, Kumagai T, Asai K, Machida M, Nierman WC, Denning DW, Caddick M, Hynes M, Paoletti M, Fischer R, Miller B, Dyer P, Sachs MS, Osmani SA, Birren BW: Sequencing of Aspergillus nidulans and comparative analysis with $\mathbf{A}$. fumigatus and $\mathbf{A}$. oryzae. Nature 2005, 438: I 105-1115.

5. Kawaguchi R, Bailey-Serres J: mRNA sequence features that contribute to translational regulation in Arabidopsis. Nucleic Acids Res 2005, 33:955-965.

6. Hinnebusch AG: Translational regulation of yeast GCN4. A window on factors that control initiator-trna binding to the ribosome. J Biol Chem 1997, 272:2 I66I-2I 664.

7. Law GL, Raney A, Heusner C, Morris DR: Polyamine regulation of ribosome pausing at the upstream open reading frame of S-adenosylmethionine decarboxylase. J Biol Chem 200I, 276:38036-38043.

8. Hanfrey C, Elliott KA, Franceschetti M, Mayer MJ, Illingworth C, Michael AJ: $A$ dual upstream open reading frame-based autoregulatory circuit controlling polyamine-responsive translation. I Biol Chem 2005, 280:39229-39237.

9. Wiese A, Elzinga $N$, Wobbes $B$, Smeekens S: A conserved upstream open reading frame mediates sucrose-induced repression of translation. Plant Cell 2004, 16:1717-1729.

10. Ghilardi N, Wiestner A, Kikuchi M, Ohsaka A, Skoda RC: Hereditary thrombocythaemia in a Japanese family is caused by a novel point mutation in the thrombopoietin gene. $\mathrm{Br} J \mathrm{Hae}-$ matol 1999, 107:310-316.

11. Kozak M: An analysis of 5'-noncoding sequences from 699 vertebrate messenger RNAs. Nucleic Acids Res 1987, I 5:8|25-8|48.

12. Jin X, Turcott E, Englehardt S, Mize GJ, Morris DR: The two upstream open reading frames of oncogene $\mathrm{mdm} 2$ have different translational regulatory properties. J Biol Chem 2003, 278:257|6-2572I

13. Child SJ, Miller MK, Geballe AP: Cell type-dependent and -independent control of HER-2/neu translation. Int J Biochem Cell Biol 1999, 31:201-213.

14. Alves de Almeida R, Heuser T, Blaschke R, Bartram CR, Janssen JW: Control of MYEOV protein synthesis by upstream open reading frames. J Biol Chem 2006, 28 I:695-704.

15. Pratt MA, White D, Kushwaha N, Tibbo E, Niu MY: Cytoplasmic mutant $\mathrm{p} 53$ increases $\mathrm{Bcl}-2$ expression in estrogen receptorpositive breast cancer cells. Apoptosis 2007, 1 2:657-669.

16. Calkhoven CF, Muller C, Martin R, Krosl G, Pietsch H, Hoang T, Leutz A: Translational control of SCL-isoform expression in hematopoietic lineage choice. Genes Dev 2003, 17:959-964.

17. Geballe AP, Sachs MS: Translational control by upstream open reading frames. In Translational control of gene expression Edited by: Sonenberg N, Hershey JWB and Mathews MB. Cold Spring Harbor, New York, CSHL Press; 2000:595-6I4.

18. Crowe ML, Wang XQ, Rothnagel JA: Evidence for conservation and selection of upstream open reading frames suggests probable encoding of bioactive peptides. BMC Genomics 2006, 7:16.

19. Hayden CA, Jorgensen RA: Identification of novel conserved peptide uORF homology groups in Arabidopsis and rice reveals ancient eukaryotic origin of select groups and preferential association with transcription factor-encoding genes. BMC Biol 2007, 5:32.

20. Neafsey DE, Galagan JE: "Dual Modes of Natural Selection on Upstream Open Reading Frames". Mol Biol Evol 2007, 24(8): $|744-5|$. Epub 2007 May 9.

21. Zhang Z, Dietrich FS: Identification and characterization of upstream open reading frames (uORF) in the 5 ' untranslated regions (UTR) of genes in Saccharomyces cerevisiae. Curr Genet 2005, 48:77-87.
22. Misra S, Crosby MA, Mungall $C$, Matthews BB, Campbell KS, Hradecky P, Huang Y, Kaminker JS, Millburn GH, Prochnik SE, Smith CD, Tupy JL, Whitfied EJ, Bayraktaroglu L, Berman BP, Bettencourt BR, Celniker SE, de Grey AD, Drysdale RA, Harris NL, Richter J, Russo S, Schroeder AJ, Shu SQ, Stapleton M, Yamada C, Ashburner M, Gelbart WM, Rubin GM, Lewis SE: Annotation of the Drosophila melanogaster euchromatic genome: a systematic review. Genome Biol 2002, 3:RESEARCH0083.

23. Inlow JK, Restifo LL: Molecular and comparative genetics of mental retardation. Genetics 2004, 166:835-88I.

24. Komonyi O, Papai G, Enunlu I, Muratoglu S, Pankotai T, Kopitova D, Maroy P, Udvardy A, Boros I: DTL, the Drosophila homolog of PIMT/TgsI nuclear receptor coactivator-interacting protein/RNA methyltransferase, has an essential role in development. J Biol Chem 2005, 280: | 2397-I 2404.

25. Blumenthal T: Operons in eukaryotes. Brief Funct Genomic Proteomic 2004, 3:199-2II.

26. Mize G], Ruan H, Low J], Morris DR: The inhibitory upstream open reading frame from mammalian $S$-adenosylmethionine decarboxylase mRNA has a strict sequence specificity in critical positions. J Biol Chem 1998, 273:32500-32505.

27. Kozak M: Pushing the limits of the scanning mechanism for initiation of translation. Gene 2002, 299: I-34.

28. Assembly/Alignment/Annotation of I 2 Drosophila Species.

29. Tamura K, Subramanian S, Kumar S: Temporal patterns of fruit fly (Drosophila) evolution revealed by mutation clocks. Mol Biol Evol 2004, 2 1:36-44.

30. Cavener DR, Ray SC: Eukaryotic start and stop translation sites. Nucleic Acids Res 1991, 19:3 I85-3192.

31. Gaba A, Jacobson A, Sachs MS: Ribosome occupancy of the yeast CPAI upstream open reading frame termination codon modulates nonsense-mediated mRNA decay. Mol Cell 2005, 20:449-460.

32. UCSC D. melanogaster genome browser.

33. Manak JR, Dike S, Sementchenko V, Kapranov P, Biemar F, Long J, Cheng J, Bell I, Ghosh S, Piccolboni A, Gingeras TR: Biological function of unannotated transcription during the early development of Drosophila melanogaster. Nat Genet 2006, 38: $1151-1158$.

34. Luukkonen BG, Tan W, Schwartz S: Efficiency of reinitiation of translation on human immunodeficiency virus type I mRNAs is determined by the length of the upstream open reading frame and by intercistronic distance. J Virol 1995, 69:4086-4094.

35. Futterer J, Hohn T: Role of an upstream open reading frame in the translation of polycistronic mRNAs in plant cells. Nucleic Acids Res 1992, 20:385I-3857.

36. Lemons D, McGinnis W: Genomic evolution of Hox gene clusters. Science 2006, 313:1918-1922.

37. Arco AD, Satrustegui J: New mitochondrial carriers: an overview. Cell Mol Life Sci 2005, 62:2204-2227.

38. Titus SA, Moran RG: Retrovirally mediated complementation of the glyB phenotype. Cloning of a human gene encoding the carrier for entry of folates into mitochondria. J Biol Chem 2000, 275:368II-368I7.

39. Hurtaud C, Gelly C, Chen Z, Levi-Meyrueis C, Bouillaud F: Glutamine stimulates translation of uncoupling protein 2mRNA. Cell Mol Life Sci 2007.

40. Krajewski S, Tanaka S, Takayama S, Schibler MJ, Fenton W, Reed JC Investigation of the subcellular distribution of the bcl-2 oncoprotein: residence in the nuclear envelope, endoplasmic reticulum, and outer mitochondrial membranes. Cancer Res 1993, 53:470|-47|4.

4I. Madani A, Soulier J, Schmid M, Plichtova R, Lerme F, Gateau-Roesch O, Garnier JP, Pla M, Sigaux F, Stern MH: The 8 kD product of the putative oncogene MTCP-I is a mitochondrial protein. Oncogene 1995, 10:2259-2262.

42. Madani A, Choukroun V, Soulier J, Cacheux V, Claisse JF, Valensi F, Daliphard S, Cazin B, Levy V, Leblond V, Daniel MT, Sigaux F, Stern $\mathrm{MH}$ : Expression of pI3MTCPI is restricted to mature T-cell proliferations with $\mathbf{t}(\mathbf{X} ; \mathbf{1 4 )}$ translocations. Blood 1996, 87:1923-1927.

43. Soulier J, Madani A, Cacheux V, Rosenzwajg M, Sigaux F, Stern MH: The MTCP-I/c6. I B gene encodes for a cytoplasmic 8 kD protein overexpressed in $T$ cell leukemia bearing a $t(X ; 14)$ translocation. Oncogene 1994, 9:3565-3570. 
44. Jin C, Myers AM, Tzagoloff A: Cloning and characterization of MRPI0, a yeast gene coding for a mitochondrial ribosomal protein. Curr Genet 1997, 3 1:228-234.

45. Nobrega MP, Bandeira SC, Beers J, Tzagoloff A: Characterization of $\mathrm{COX}$ I9, a widely distributed gene required for expression of mitochondrial cytochrome oxidase. J Biol Chem 2002, 277:40206-402II.

46. Beers J, Glerum DM, Tzagoloff A: Purification, characterization, and localization of yeast CoxI7p, a mitochondrial copper shuttle. J Biol Chem 1997, 272:33191-33196.

47. Mesecke N, Terziyska N, Kozany C, Baumann F, Neupert W, Hell K, Herrmann JM: A disulfide relay system in the intermembrane space of mitochondria that mediates protein import. Cell 2005, I 2 I:1059-1069.

48. Hofmann S, Rothbauer U, Muhlenbein N, Baiker K, Hell K, Bauer MF: Functional and mutational characterization of human MIA40 acting during import into the mitochondrial intermembrane space. I Mol Biol 2005, 353:517-528.

49. Gray MW, Burger G, Lang BF: The origin and early evolution of mitochondria. Genome Biol 200I, 2:REVIEWSI0I8.

50. Chang KS, Lee SH, Hwang SB, Park KY: Characterization and translational regulation of the arginine decarboxylase gene in carnation (Dianthus caryophyllus L.). Plant J 2000, 24:45-56.

51. Flybase [http://www.flybase.org]

52. Ensembl Anopheles resources.

53. NCBI.

54. Pairwise Ka/Ks program.

55. Tamura K, Dudley J, Nei M, Kumar S: MEGA4: Molecular Evolutionary Genetics Analysis (MEGA) software version 4.0. Mol Biol Evol 2007, 24:1596-I599.

56. Castillo-Davis $\mathrm{Cl}$, Hartl DL: GeneMerge--post-genomic analysis, data mining, and hypothesis testing. Bioinformatics 2003 | 9:89|-892.

57. GO term association files.

58. Biomart.

59. Drosophila GO term files [http://flybase.org/static pages/down loads/bulkdata7.html]

60. Interpro domain database [ftp://ftp.ebi.ac.uk/pub/databases/ interpro/entry.list]

61. Umemiya T, Takasu E, Takeichi M, Aigaki T, Nose A: Forked end: a novel transmembrane protein involved in neuromuscular specificity in drosophila identified by gain-of-function screening. J Neurobiol 2002, 5 I :205-2 I4.

62. Laviolette MJ, Nunes P, Peyre JB, Aigaki T, Stewart BA: A genetic screen for suppressors of Drosophila NSF2 neuromuscular junction overgrowth. Genetics 2005, I 70:779-792.

63. Venclovas C, Thelen MP: Structure-based predictions of Rad I, Rad9, Hus I and RadI7 participation in sliding clamp and clamp-loading complexes. Nucleic Acids Res 2000, 28:248I-2493.

64. Parker AE, Van de Weyer I, Laus MC, Oostveen I, Yon J, Verhasselt $\mathrm{P}$, Luyten WH: A human homologue of the Schizosaccharomyces pombe rad I+ checkpoint gene encodes an exonuclease. J Biol Chem 1998, 273: 18332-18339.

65. Starcevic M, Dell'Angelica EC: Identification of snapin and three novel proteins (BLOSI, BLOS2, and BLOS3/reduced pigmentation) as subunits of biogenesis of lysosome-related organelles complex-I (BLOC-I). J Biol Chem 2004, 279:28393-2840I.

66. Drapkin R, Reardon JT, Ansari A, Huang JC, Zawel L, Ahn K, Sancar $A$, Reinberg D: Dual role of TFIIH in DNA excision repair and in transcription by RNA polymerase II. Nature 1994, 368:769-772.

67. Ranish JA, Hahn S, Lu Y, Yi EC, Li XJ, Eng J, Aebersold R: Identification of TFB5, a new component of general transcription and DNA repair factor IIH. Nat Genet 2004, 36:707-7I3.

68. Freeman MR, Delrow J, Kim J, Johnson E, Doe CQ: Unwrapping glial biology: $\mathbf{G c m}$ target genes regulating glial development, diversification, and function. Neuron 2003, 38:567-580.

69. Bocca SN, Muzzopappa M, Silberstein S, Wappner P: Occurrence of a putative SCF ubiquitin ligase complex in Drosophila. Biochem Biophys Res Commun 2001, 286:357-364.

70. Taylor CA, Stanley KN, Shirras AD: The Orct gene of Drosophila melanogaster codes for a putative organic cation transporter with six or 12 transmembrane domains. Gene 1997, 201:69-74.
7I. Kraut R, Menon K, Zinn K: A gain-of-function screen for genes controlling motor axon guidance and synaptogenesis in Drosophila. Curr Biol 200 I, I I:4 I7-430.

72. Oba Y, Sato M, Ojika M, Inouye S: Enzymatic and genetic characterization of firefly luciferase and Drosophila CG6 I 78 as a fatty acyl-CoA synthetase. Biosci Biotechnol Biochem 2005, 69:819-828

73. Vogel C, Teichmann SA, Chothia C: The immunoglobulin superfamily in Drosophila melanogaster and Caenorhabditis elegans and the evolution of complexity. Development 2003, I30:6317-6328

74. MacLaren CM, Evans TA, Alvarado D, Duffy JB: Comparative analysis of the Kekkon molecules, related members of the LIG superfamily. Dev Genes Evol 2004, 2 I 4:360-366.

75. Mohler J, Wieschaus EF: Dominant maternal-effect mutations of Drosophila melanogaster causing the production of double-abdomen embryos. Genetics 1986, I I 2:803-822.

76. Saffman EE, Styhler S, Rother K, Li W, Richard S, Lasko P: Premature translation of oskar in oocytes lacking the RNA-binding protein bicaudal-C. Mol Cell Biol 1998, I 8:4855-4862.

77. Castagnetti S, Ephrussi $A$ : Orb and a long poly(A) tail are required for efficient oskar translation at the posterior pole of the Drosophila oocyte. Development 2003, I30:835-843.

78. Li C, Harding GA, Parise J, McNamara-Schroeder KJ, Stumph WE: Architectural arrangement of cloned proximal sequence element-binding protein subunits on Drosophila UI and U6 snRNA gene promoters. Mol Cell Biol 2004, 24: I897-I906.

79. Lee YJ, Shah S, Suzuki E, Zars T, O'Day PM, Hyde DR: The Drosophila dgq gene encodes a $\mathbf{G}$ alpha protein that mediates phototransduction. Neuron 1994, I3: I |43-I I57.

80. Scott K, Becker A, Sun Y, Hardy R, Zuker C: Gq alpha protein function in vivo: genetic dissection of its role in photoreceptor cell physiology. Neuron 1995, 15:919-927.

81. Ratnaparkhi A, Banerjee S, Hasan G: Altered levels of $\mathbf{~ G q}$ activity modulate axonal pathfinding in Drosophila. J Neurosci 2002, 22:4499-4508.

82. Santos AC, Lehmann R: Isoprenoids control germ cell migration downstream of HMGCoA reductase. Dev Cell 2004, 6:283-293.

83. Kasai T, Inoue M, Koshiba S, Yabuki T, Aoki M, Nunokawa E, Seki E, Matsuda T, Matsuda N, Tomo Y, Shirouzu M, Terada T, Obayashi N, Hamana H, Shinya N, Tatsuguchi A, Yasuda S, Yoshida M, Hirota H, Matsuo Y, Tani K, Suzuki H, Arakawa T, Carninci P, Kawai J, Hayashizaki Y, Kigawa T, Yokoyama S: Solution structure of a BolA-like protein from Mus musculus. Protein Sci 2004, I 3:545-548.

84. Gundelfinger ED, Hermans-Borgmeyer I, Grenningloh G, Zopf D: Nucleotide and deduced amino acid sequence of the phosphoenolpyruvate carboxykinase (GTP) from Drosophila melanogaster. Nucleic Acids Res 1987, I 5:6745.

85. Zinke I, Kirchner C, Chao LC, Tetzlaff MT, Pankratz MJ: Suppression of food intake and growth by amino acids in Drosophila: the role of pumpless, a fat body expressed gene with homology to vertebrate glycine cleavage system. Development 1999, I 26:5275-5284.

86. Okamura T, Shimizu H, Nagao T, Ueda R, Ishii S: ATF-2 regulates fat metabolism in Drosophila. Mol Biol Cell 2007, 1 8:1519-1529.

87. Doerks T, Copley RR, Schultz J, Ponting CP, Bork P: Systematic identification of novel protein domain families associated with nuclear functions. Genome Res 2002, I 2:47-56.

88. Webb CT, Gorman MA, Lazarou M, Ryan MT, Gulbis JM: Crystal structure of the mitochondrial chaperone TIM9.10 reveals a six-bladed alpha-propeller. Mol Cell 2006, 2 I: I23-I33.

89. Williams BC, Garrett-Engele CM, Li Z, Williams EV, Rosenman ED, Goldberg ML: Two putative acetyltransferases, san and deco, are required for establishing sister chromatid cohesion in Drosophila. Curr Biol 2003, 13:2025-2036.

90. Belyaeva ES, Zhimulev IF, Volkova El, Alekseyenko AA, Moshkin YM, Koryakov DE: Su(UR)ES: a gene suppressing DNA underreplication in intercalary and pericentric heterochromatin of Drosophila melanogaster polytene chromosomes. Proc Nat Acad Sci U S A 1998, 95:7532-7537.

91. Tchurikov NA, Kretova OV, Chernov BK, Golova YB, Zhimulev IF, Zykov IA: SuUR protein binds to the boundary regions separating forum domains in Drosophila melanogaster. J Biol Chem 2004, 279: I 1705-11710. 
92. Marenda DR, Zraly CB, Dingwall AK: The Drosophila Brahma (SWI/SNF) chromatin remodeling complex exhibits celltype specific activation and repression functions. Dev Biol 2004, 267:279-293.

93. Pandey R, Muller A, Napoli CA, Selinger DA, Pikaard CS, Richards EJ, Bender J, Mount DW, Jorgensen RA: Analysis of histone acetyltransferase and histone deacetylase families of Arabidopsis thaliana suggests functional diversification of chromatin modification among multicellular eukaryotes. Nucleic Acids Res 2002, 30:5036-5055

94. Kent D, Bush EW, Hooper JE: Roadkill attenuates Hedgehog responses through degradation of Cubitus interruptus. Development 2006, 133:200I-2010.

95. Nybakken K, Vokes SA, Lin TY, McMahon AP, Perrimon N: A genome-wide RNA interference screen in Drosophila melanogaster cells for new components of the Hh signaling pathway. Nat Genet 2005, 37:1323-1332.

96. Reiss J, Dorche C, Stallmeyer B, Mendel RR, Cohen N, Zabot MT: Human molybdopterin synthase gene: genomic structure and mutations in molybdenum cofactor deficiency type $B$. Am J Hum Genet 1999, 64:706-7II.

Publish with Bio Med Central and every scientist can read your work free of charge

"BioMed Central will be the most significant development for disseminating the results of biomedical research in our lifetime. "

Sir Paul Nurse, Cancer Research UK

Your research papers will be:

- available free of charge to the entire biomedical community

- peer reviewed and published immediately upon acceptance

- cited in PubMed and archived on PubMed Central

- yours - you keep the copyright 